\title{
ANALISIS PROKSIMAT PADA BRIKET ARANG LIMBAH PERTANIAN
}

\author{
Leni Rumiyanti $^{1, \text { a) }}$, Annisa Irnanda ${ }^{1, b)}$, Yusup Hendronursito ${ }^{2}$ \\ ${ }^{1}$ Jurusan Fisika FMIPA Universitas Lampung Jl. S. Brojonegoro No 1, Bandar Lampung 35144 \\ ${ }^{2}$ Balai Penelitian Teknologi Mineral - LIPI
}

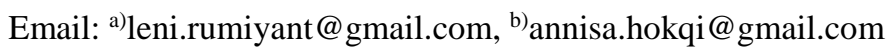

\begin{abstract}
Abstrak
Telah dilakukan penelitian yang bertujuan untuk mengetahui kualitas briket arang terbaik dan terburuk dari limbah pertanian berdasarkan kandungan proksimatnya. Limbah pertanian yang digunakan adalah sekam padi, ampas tebu, kulit singkong, tongkol jagung, dan batok kelapa. Metode penelitian yang digunakan adalah karbonisasi pirolisis pada suhu 700-800 oC selama 45 menit dan dianalisis proksimat dengan teknik yang sesuai Standar Nasional Indonesia (SNI) untuk pengujian kadar air lembab, abu, zat terbang, dan karbon tertambat. Hasil penelitian menunjukkan bahwa kualitas briket arang terbaik adalah kulit singkong karena memiliki kadar air dan abu terendah, yaitu 0,3833\% dan 0,8452\%. Sementara, kualitas briket arang terburuk adalah tongkol jagung karena memiliki kadar air tertinggi yaitu 2,412\% dan karbon tertambat terendah yaitu 71,442\%.
\end{abstract}

Kata kunci: briket arang, limbah pertanian, analisis proksimat.

\begin{abstract}
Research has been conducted to know the best and worst quality of charcoal briquettes from agricultural wastes based on their proximate content. These agrarian wastes are rice husk, sugarcane baggage, cassava peel, corncob, and coconut shell. The research method is pyrolysis carbonization at 700-800 oC for $45 \mathrm{~min}$ and proximate analysis with techniques that suitable Indonesian National Standard (SNI) for testing of moisture, ash, volatile matter, and fixed carbon content. The research result showed that the best charcoal briquettes quality is cassava peel because it has the lowest water content of $0.3833 \%$ and the lowest ash content of $0.8452 \%$. While the worst charcoal briquettes quality is corncob because it has the highest water content of $2,412 \%$ and the lowest fixed carbon of $71,442 \%$.
\end{abstract}

Keywords: charcoal briquettes, agricultural wastes, proximate analysis.

\section{PENDAHULUAN}

Indonesia yang saat ini terfokus pada bahan bakar minyak harus menghadapi krisis produksi yang terus menurun dan beban impor minyak. Hal ini disebabkan karena tidak mampu memasok kebutuhan dalam negeri hingga Indonesia harus menjadi importir dalam empat tahun terakhir [1]. Produksi minyak di Indonesia turun pada kisaran satu juta barrel per hari, sementara kebutuhan mencapai 1,3 juta barrel per hari. Berdasarkan rencana dasar atau "blueprint" Pengelolaan Energi Nasional 2005-2025 hasil penyusunan Departemen Energi dan Sumber Daya Mineral, cadangan 
minyak di Indonesia yang berjumlah 9 miliar barel dengan tingkat produksi 500 juta barel per tahun, diprediksi bakal habis dalam waktu 18 tahun. Oleh karena itu, saat ini kelangsungan industri minyak masih sangat dibutuhkan sebab belum ada alternatif pengganti. Energi alternatif yang biasa dikembangkan sebagai pengganti dari minyak bumi, antara lain gas bumi, batu bara, arang kayu, dan biomassa [2]. Indonesia sebagai negara agraris banyak menghasilkan limbah pertanian seperti sekam padi, ampas tebu, kulit singkong, tongkol jagung, dan tempurung kelapa yang sampai saat ini belum dimanfaatkan secara optimal. Pemanfaatan limbah pertanian sebagai bahan baku dalam pembuatan briket arang merupakan salah satu bahan bakar alternatif yang tepat sebagai sumber bahan bakar untuk mengurangi pengunaan minyak tanah karena selain tahan lebih lama daripada arang biasa, bahan bakunya pun mudah didapat.

Biomassa disebut juga sebagai "fitomassa" dan sering diterjemahkan sebagai bioresource atau sumber daya yang diperoleh dari hayati [3]. Biomassa adalah suatu limbah benda padat yang bisa dimanfaatkan sebagai sumber bahan bakar. Energi biomassa dapat menjadi sumber energi alternatif pengganti bahan bakar fosil (minyak bumi) karena sifatnya yang dapat diperbaharui dan relatif tidak mengandung unsur sulfur sehingga tidak menyebabkan polusi udara [4]. Biomassa dapat digunakan melalui proses pengolahan, salah satunya adalah menjadi briket arang. Faktor-faktor yang mempengaruhi sifat briket arang adalah berat jenis bahan bakar atau berat jenis serbuk arang, kehalusan serbuk, suhu karbonisasi dan tekanan pada saat dilakukan pencetakan. Akan tetapi, untuk memaksimalkan pemanfaatannya, biomassa ini masih harus melalui sedikit proses pengolahan sehingga menjadi briket biomassa. Briket biomassa adalah gumpalan-gumpalan atau batanganbatangan arang yang terbuat dari biomassa (bahan lunak). Biomassa yang sebenarnya termasuk bahan lunak yang dengan proses tertentu diolah menjadi bahan arang keras. Kualitas dari biomassa ini tidak kalah dengan batubara atau bahan bakar jenis arang lainnya [5].

Limbah pertanian seperti sekam padi, ampas tebu, kulit singkong, tongkol jagung, dan batok kelapa adalah biomassa yang dapat dijadikan sebagai bahan pembuatan briket. Sekam padi memiliki nilai kalori sebesar $3300 \mathrm{kal} / \mathrm{gr}$, artinya sekam dapat dimanfaatkan sebagai sumber energi panas untuk keperluan manusia. Kadar selulosa sekam yang cukup tinggi dapat memberikan pembakaranyang merata dan stabil [11]. Ampas tebu memiliki sifat mudah terbakar karena di dalamnya terkandung air, gula, serat dan mikroba, sehingga bila tertumpuk akan terfermentasi dan melepaskan panas [14]. Briket dari ampas tebu akan lebih terjamin sebab bersifat renewable (mudah diperbaharui). Penelitian sebelumnya [16] menunjukkan bahwa nilai kalor briket arang kulit singkong sebesar $3785 \mathrm{kal} / \mathrm{gr}$ sehingga dapat dijadikan sumber energi panas. Menurut Badan Pusat Statistik (BPS) [13], produksi jagung tahun 2015 diperkirakan sebanyak 20,67 juta ton pipilan kering. Buah jagung terdiri dari 30\% limbah yang berupa tongkol jagung [12]. Dengan angka tersebut, produksi yang semakin meningkat setiap tahunnya akan menghasilkan limbah jagung yang semakin banyak, sehingga jika tidak dimanfaatkan dengan baik maka hanya akan menjadi sampah. Batok kelapa adalah salah satu bahan karbon aktif yang kualitasnya cukup baik dijadikan arang aktif. Arang aktif dari batok kelapa memiliki daya saing yang kuat karena mutunya tinggi dan tergolong sumber daya yang terbarukan [15].

Briket bioarang mempunyai beberapa kelebihan dibandingkan arang biasa (konvensional) antara lain (1) bioarang menghasilkan panas pembakaran yang lebih tinggi, (2) Asap yang dihasilkannya lebih sedikit, (3) bentuk dan ukuran bioarang seragam karena dibuat dengan alat pencetak, (4) bioarang dapat tampil lebih menarik karena bentuk dan ukurannya dapat disesuaikan keinginan pembuat, dan (5) proses pembuatannya menggunakan bahan baku yang tidak menimbulkan masalah lingkungan [3]. Proses karbonisasi atau pengarangan adalah proses mengubah bahan baku asal menjadi karbon berwarna hitam melalui pembakaran dalam ruang tertutup dengan udara yang terbatas atau seminimal mungkin. Lamanya pengarangan ditentukan oleh jumlah atau volume bahan organik, ukuran parsial bahan, kerapatan bahan, tingkat kekeringan bahan, jumlah oksigen yang masuk, dan asap yang keluar dari ruang pembakaran [6].

Pada penelitian ini pengarangan limbah pertanian berupa briket arang sekam padi, ampas tebu, kulit singkong, tongkol jagung, dan batok kelapa akan dianalisis kandungan proksimatnya untuk mengetahui kualitas terbaik dan terburuk dari limbah pertanian tersebut. 


\section{METODE PENELITIAN}

Metode penelitian yang digunakan adalah karbonisasi pirolisis pada suhu $700-800{ }^{\circ} \mathrm{C}$ selama 45 menit. Teknik ini akan mengubah limbah pertanian menjadi arang. Ketika pencetakan briket, arang tongkol jagung menggunakan tekanan 4 ton yang berbeda dengan arang lainnya yang menggunakan 5 ton. Hal ini dikarenakan campuran antara arang dan perekat yang terlalu basah sehingga ketika pencetakan banyak campuran yang keluar melalui sela-sela wadah cetakan.

Kualitas dari sebuah briket dapat dilihat melalui analisis proksimat (proximate analysis) yang dilakukan agar dapat diketahui kandungan air lembab, abu, zat terbang, dan karbon tertambat di dalam briket. Analisis proksimat ini dilakukan dengan teknik yang sesuai dengan Standar Nasional Indonesia (SNI).

Kandungan air lembab ditentukan dengan perhitungan [7] berikut ini.

$$
M_{a d}(\%)=\frac{m_{2}-m_{3}}{m_{2}-m_{1}} \times 100 \%
$$

Kandungan abu ditentukan dengan perhitungan [8] berikut ini.

$$
A(\%)=\frac{m_{3}-m_{1}}{m_{2}} \times 100 \%
$$

Kandungan zat terbang ditentukan dengan perhitungan [9] berikut ini.

$$
V M(\%)=\frac{m_{2}-m_{3}}{m_{2}-m_{1}} \times 100 \%-M_{a d}
$$

Kandungan karbon tertambat ditentukan dengan perhitungan [10] berikut ini.

$$
F C(\%)=100 \%-\left(M_{a d}-A-\mathrm{V} M\right) \%
$$

Keterangan:

$M=$ Kadar air total (\%)

$M_{\text {ad }}=$ Kadar air lembab $(\%)$

$V M=$ kadar zat terbang $(\%)$

$A=$ Kadar abu $(\%)$

$F C=$ Kadar karbon tertambat $(\%)$

$m_{1}=$ Berat cawan $(\mathrm{g})$

$m_{2}=$ Berat cawan dan arang sebelum dipanaskan $(\mathrm{g})$

$m_{3}=$ Berat cawan dan arang setelah dipanaskan $(\mathrm{g})$ 
Diagram alir pada penelitian ini dijelaskan GAMBAR 1 berikut ini.

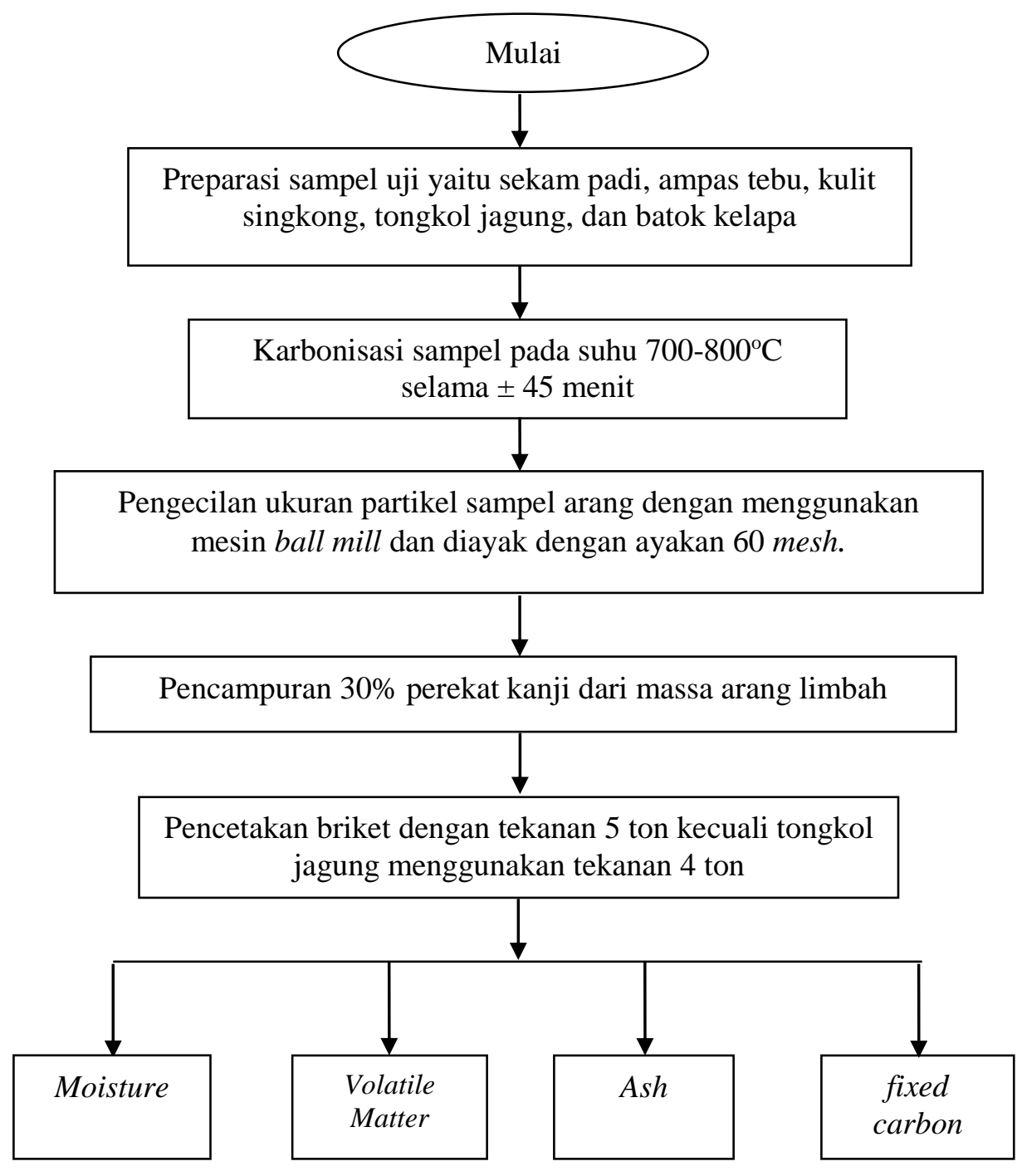

GAMBAR 1. Diagram Alir Penelitian

\section{HASIL DAN PEMBAHASAN}

Berdasarkan penelitian yang telah dilakukan, diperoleh hasil analisis proksimat (TABEL 1) .

TABEL 1. Hasil Analisis Proksimat Limbah Pertanian.

\begin{tabular}{lcccc}
\hline \multicolumn{1}{c}{ Briket Arang } & Mad $_{\text {ad }}$ & A & VM & FC \\
\hline Sekam Padi & 0,629 & 2,316 & 7,606 & 89,449 \\
Ampas Tebu & 0,602 & 0,887 & 17,575 & 80,937 \\
Kulit Singkong & 0,383 & 0,845 & 20,749 & 78,023 \\
Tongkol Jagung & 2,412 & 1,235 & 24,912 & 71,442 \\
Batok Kelapa & 0,438 & 1,837 & 23,213 & 74,074 \\
\hline
\end{tabular}




\section{Kadar Air}

Dalam analisis proksimat, kadar air terdiri dari kadar air total dan kadar air lembab. Kadar air total tertinggi diperoleh pada briket arang tongkol jagung yaitu sebesar 29,0915\%, sedangkan kadar air total yang paling rendah diperoleh pada briket arang sekam padi yaitu sebesar 5,6025\%. Hal ini disebabkan karena pada arang tongkol jagung memiliki ukuran yang paling halus yang menyebabkan pori-pori arang semakin besar sehingga arang tersebut akan lebih mudah menyerap air dari udara dan memberikan penambahan air di dalam arang. Jika dilihat dari kadar air total, briket arang sekam padi memiliki kualitas paling baik dibandingkan briket arang lainnya.

Kadar air lembab terendah diperoleh pada briket arang kulit singkong yaitu sebesar 0,3833\%, sedangkan kadar air lembab tertinggi diperoleh pada briket arang tongkol jagung yaitu sebesar $2,412 \%$. Pada umumnya, kadar air lembab yang tinggi akan menurunkan nilai kalor dan laju pembakaran. Briket yang mengandung kadar air yang tinggi akan mudah hancur serta mudah ditumbuhi jamur.

Kadar air total dan kadar air lembab mempengaruhi kualitas briket yang dihasilkan. Kadar air pada briket diharapkan serendah mungkin agar dapat menghasilkan nilai kalor yang tinggi dan akan menghasilkan briket yang mudah dalam penyalaan atau pembakaran awalnya. Semakin rendah kadar air, semakin tinggi nilai kalor dan daya pembakarannya. Sebaliknya, briket dengan kadar air yang tinggi akan menyebabkan nilai kalor yang dihasilkan briket tersebut menurun. Hal ini disebabkan energi yang dihasilkan akan banyak teresap untuk menguapkan air.

\section{Kadar Zat Terbang}

Kadar zat terbang pada suhu $950^{\circ} \mathrm{C}$ adalah zat yang dapat menguap sebagai hasil karbonisasi senyawa-senyawa yang masih terdapat di dalam briket arang selain air, karbon tertambat dan abu. Kadar zat terbang terendah diperoleh pada briket arang sekam padi yaitu sebesar 7,6057\% dan tertinggi pada briket arang tongkol jagung yaitu sebesar 24,9115\%. Pada penelitian sebelumnya [17] kadar zat terbang dengan suhu karbonisasi $380{ }^{\circ} \mathrm{C}$ menghasilkan $15,632 \%$. Hal ini menunjukkan semakin tinggi suhu karbonisasi, kadar zat terbang yang dihasilkan semakin besar. Tinggi rendahnya volatile matter banyak dipengaruhi oleh tidak optimalnya proses karbonisasi. Tujuan karbonasi untuk menguraikan senyawa hidrokarbon seperti selulosa dan hemiselulosa agar menjadi karbon murni.

Semakin besar suhu dan waktu dalam proses pengarangan maka semakin banyak zat terbang yang terbuang sehingga pada saat pengujian kadar zat terbang akan diperoleh kadar zat terbang yang rendah. Tinggi rendahnya kadar zat terbang juga mempengaruhi briket arang mudah terbakar atau tidak, dimana semakin tinggi kadar zat terbang maka semakin mudah briket arang terbakar. Pada penelitian ini, briket arang yang mudah terbakar karena memiliki kadar zat terbang tertinggi adalah briket arang tongkol jagung.

\section{Kadar Abu}

Kadar abu yang dihasilkan dari penelitian ini yaitu berkisar antara 0,8-2,4\%. Hasil yang diperoleh pada briket arang limbah pertanian ini sesuai dengan SNI 01-6235-2000 yaitu kadar abu briket maksimal $8 \%$.

Kadar abu tertinggi diperoleh pada briket arang sekam padi yaitu sebesar 2,3159\%, sedangkan kadar abu terendah diperoleh pada briket arang kulit singkong yaitu sebesar 0,8452\%. Pada penelitian sebelumnya [16] dengan campuran bahan perekat $10 \%$ menghasilkan kadar abu terendah sebesar $1,235 \%$. Hal ini menunjukkan semakin banyak campuran perekat, kadar abu yang dihasilkan semakin kecil.

Kadar abu yang tinggi akan menimbulkan kerak serta dapat menurunkan kualitas briket yang dihasilkan karena dapat menurunkan nilai kalor dan laju pembakaran dari briket. Oleh karena itu, pada pembuatan briket sebisa mungkin memiliki kandungan abu yang sangat rendah. Apabila dikaitkan dengan kadar air dan nilai kalor briket terlihat bahwa pada perlakuan briket yang memiliki kadar abu yang rendah, juga memiliki kadar air yang rendah, sehingga briket tersebut memiliki nilai 
kalor yang tinggi. Pada penelitian ini, briket yang memiliki kualitas baik karena memiliki kadar abu yang rendah yaitu briket arang kulit singkong.

\section{Kadar Karbon tertambat}

Kadar karbon tertambat (fixed carbon) dipengaruhi oleh perubahan kadar abu, kadar air, dan zat volatile matter briket arang dari limbah pertanian ini. Kadar fixed carbon yang dihasilkan berkisar antara $71-90 \%$. Kadar fixed carbon tertinggi yaitu pada briket arang sekam padi sebesar $89,4496 \%$ dan kadar fixed carbon terendah yaitu pada briket arang tongkol jagung sebesar $71,442 \%$. Penelitian ini tidak dilakukan uji XRF sehingga tidak diketahui kandungan silika yang terkandung pada briket arang sekam padi.

Kadar karbon tertambat (fixed carbon) yang tinggi menunjukkan kualitas arang yang baik. Semakin tinggi nilai kadar kabon terikat, maka kualitas arang akan semakin baik. Begitupun sebaliknya, semakin rendah nilai karbon tertambat maka kualitas arang akan semakin buruk. Pada penelitian ini, briket arang yang paling baik dengan kadar karbon tertambat tertinggi adalah briket arang sekam padi. Sedangkan briket arang yang kurang baik dengan kadar karbon tertambat terendah adalah briket arang tongkol jagung.

\section{KESIMPULAN}

Pada penelitian ini, yang memiliki kualitas briket arang terbaik adalah kulit singkong karena memiliki kadar air yang terendah yaitu sebesar 0,3833\% dan kadar abu terendah yaitu sebesar $0,8452 \%$. Sementara, kualitas terburuk adalah tongkol jagung karena memiliki kadar air tertinggi yaitu sebesar 2,412\% dan kadar karbon tertambat terendah yaitu sebesar 71,442\%.

\section{UCAPAN TERIMAKASIH}

Terimakasih kepada Jurusan Fisika Material Fakultas Matematika Dan Ilmu Pengetahuan Alam dan Balai Penelitian Teknologi Mineral - LIPI yang telah memberikan tempat untuk melakukan penelitian ini serta kepada pihak-pihak yang telah mendukung dan membantu dalam menyelesaikan penelitian ini.

\section{REFERENSI}

[1] Santosa, Iwan. 2004, 25 September. Revolusi Energi atau Mati. Energi LIPI [Online]. Diakses pada tanggal 18 Februari 2017.

[2] Risna. 2016. Pengaruh Tekanan Dan Ukuran Partikel Terhadap Kualitas Briket Arang Cangkang Coklat. Universitas Halu Oleo. Kendari.

[3] Setiawan. 2007. Memanfaatkan Kotoran Ternak, Solusi Masalah Lingkungan Dan Pemanfaatan Energi Alternatif. Penebar Swadaya. Depok.

[4] Sinurat, E. 2011. Studi pemanfaatan briket kulit jambu mete dan tongkol jagung sebagai bahan bakar alternatif. Universitas Hasanuddin. Makassar.

[5] Elfiano, E., Subekti, P., dan Sadil, A. 2014. Analisa Proksimat Dan Nilai Kalor Pada Briket Biomassa Limbah Ampas Tebu Dan Arang Kayu. Jurnal Aptek. Vol. 6 No. 1 pp. 58

[6] Delly, J dan Saputra, N. 2014. Proses Pembuatan Briket Berbasis Kulit Singkong Dan Kajian Eksperimen Parametris Pengaruh Bahan Perekatnya Terhadap Nilai Kalor Dan Laju Pembakaran. Jurnal Ilmiah Teknik Mesin. Vol. 6, No. 1. Hal. 4

[7] SNI 13-3477-1994 : Analisis Kadar Air Lembab dari Contoh Batubara Kering Udara.

[8] SNI 13-3478-1994 : Analisis Kadar Abu Contoh Batubara.

[9] SNI 13-3999-1995 : Analisis Kadar Zat Terbang (Volatile) Contoh Batubara. 
[10] SNI 13-3479-1994 : Analisis Kadar Karbon Tertambat Contoh Batubara.

[11] Sipahutar, D. 2010. Teknologi Briket Sekam Padi. Badan Pelayanan Perizinan Terpadu. Riau.

[12] Subekti. 2006. Produksi Etanol dari Hidrolisat Fraksi Selulosa Tongkol Jagung oleh Saccharomyces Cerevisiae. Institut Pertanian Bogor. Bogor.

[13] BPS. 2015. Produksi Padi, Jagung, dan Kedelai. Berita Resmi Statistik. No. 28/03/Th. XVIII, 2 Maret 2015.

[14] Nugraha, J. R. 2013. Karakteristik Termal Briket Arang Ampas Tebu dengan Variasi Bahan Perekat Lumpur Lapindo. Skripsi. Universitas Jember. Jember.

[15] Mahmud, Z dan Ferry, Y. 2005. Prospek Pengolahan Hasil Samping Buah Kelapa. Perspektif. Vol. 4, No. 2. Hal 55-63.

[16] Moeksin, R., M. T., dan Kunchoro, A. 2015. Pengaruh Komposisi Pembuatan Biobriket dari Campuran Serbuk Gergaji, Kulit Singkong, dan Batubara terhadap Nilai Pembakaran. Jurnal Teknik Kimia. Vol. 21, No. 4. Hal 19-26.

[17] Surono, U. B. 2010. Peningkatan Kualitas Pembakaran Biomassa Limbah Tongkol Jagung sebagai Bahan Bakar Alternatif dengan Proses Karbonisasi dan Pembriketan. Jurnal Rekayasa Proses. Vol. 4, No. 1. Hal 13-18. 
Spektra: Jurnal Fisika dan Aplikasinya http://doi.org/10.21009/SPEKTRA
Volume 3 Nomor 1, April 2018
p-ISSN: 2541-3384

e-ISSN: 2541-3392 